\title{
REAKSI PASAR MODAL INDONESIA TERHADAP PENGUMUMAN INDONESIA SEBAGAI NEGARA MAJU
}

\author{
Ely Damayanti ${ }^{1}$, Rahayu Dwi Larasati ${ }^{2}$, Kharis Fadlullah Hana ${ }^{3}$ \\ ${ }^{1}$ IAIN Kudus, Ekonomi Syariah, Fakultas Ekonomi dan Bisnis Islam \\ ${ }^{2}$ IAIN Kudus, Ekonomi Syariah, Fakultas Ekonomi dan Bisnis Islam \\ ${ }^{3}$ IAIN Kudus \\ elydamayanti720@gmail.com ${ }^{1}$, larasatidwi064@gmail.com² ${ }^{2}$ kharis@iainkudus.ac.id $^{3}$
}

\begin{abstract}
ABSTRAK
Tujuan dari penelitian ini adalah untuk menganalisis perbedaan abnormal return sebelum dan sesudah pengumuman Indonesia sebagai negara maju pada indeks saham LQ45. Penelitian ini menggunakan metode purposive sampling dengan sampel sebanyak 45 perusahaan. Data yang digunakan adalah data sekunder yang diambil dari situs resmi Bursa Efek Indonesia yaitu www.idx.co.id. Pengujian dilakukan menggunakan paired sample $t$ test dengan periode jendela peristiwa 15 hari. Yaitu tujuh hari sebelum event day dan tujuh hari setelah event day. Hasil analisis statistik menunjukkan bahwa tidak adanya rata-rata abnormal return yang signifikan sebelum dan sesudah peristiwa pengumuman Indonesia sebagai negara maju. Artinya reaksi pasar yang sebagian besar tidak signifikan ini mengakibatkan secara statistik tidak terdapat perbedaan rata-rata abnormal return yang signifikan pada pengumuman Indonesia sebagai negara maju.
\end{abstract}

Kata Kunci: Abnormal Return, Pengumuman Indonesia Sebagai Negara Maju, LQ45, Event Study

\begin{abstract}
The purpose of this tdudy is to analyze the differences in abnormal return before and after the announcement of Indonesia as a developed country on the LQ45 stock index. This study uses a purposive sampling method with a sample of 45 companies. The data used are secondary data taken from the official website of the Indonesia Stock Exchange, www.idx.co.id. Tests were carried out using paired sample $t$ test with a 15 day event window period. That is, seven days before the event day and sevend days after the event day. The result of statistical analysys shows that there is no significant average abnormal return and after the announcement of Indonesia as a developed country. This means that the market reaction, is largely insignificant, result in a statistically significant difference in the average abnormal return on Indonesia's announcement as a development country.
\end{abstract}

Keywords: Abnormal Return, Pengumuman Indonesia Sebagai Negara Maju, LQ45, Event Study 


\section{PENDAHULUAN}

Sekarang ini, investasi di pasar modal kian memarak. Hal itu dibuktikan dengan bertambahnya jumlah perusahaan yang terdaftar di Bursa Efek Indonesia maupun jumlah investor yang ada. Sementara itu pergerakan indeks harga saham gabungan (IHSG) selama pemerintahan Presiden Joko Widodo pada periode 2014 hingga 2019 terpantau variatif (Tari 2019). Bursa Efek Indonesia melaporkan pertumbuhan positif atas jumlah investor di pasar modal Indonesia (Movanita 2019). Di dalam pasar modal, Indeks Harga Saham Gabungan (IHSG) di sepanjang tahun 2019 masih menunjukkan pertumbuhan yang positif sebesar $1,70 \%$, ditutup di level 6.299,5. Net buy investor asing di pasar saham mengalami peningkatan signifikan, dari mencatat net sell $\mathrm{Rp} 50,7$ Triliun di 2018 menjadi net buy Rp 49,2 T di tahun 2019 (Wareza 2020).

Per mei 2019, ada total 1,9 juta investor di pasar modal. Namun, baru-baru ini media telah memberitakan bahwa pemerintah Amerika Serikat telah menerbitkan Federal Register Vol. 82, No. 27 pada 10 Februari yang di dalamnya memuat pengumuman dari United States Trade Representatives (USTR). Dalam pengumuman itu Indonesia dicabut dari daftar negara berkembang (Benyamin and Andri 2020). Pencabutan tersebut dilakukan oleh pemerintah Amerika Serikat melalui Kantor Perwakilan Perdagangan atau Office of the US Trade Representative (USTR) di Organisasi Perdagangan Dunia (WTO) (Mukaromah 2020). Hal ini dapat memancing berbagai macam respons dalam pasar modal. Namun, respons tersebut akan menimbulkan berbagai reaksi pasar modal seperti naik turunnya harga saham maupun jumlah investor, dan juga bisa menimbulkan abnormal return.
Pengumuman Indonesia sebagai negara maju merupakan peristiwa yang dimungkinkan dapat mempengaruhi aktivitas yang ada di pasar modal Indonesia. Hal ini dikarenakan informasi yang terkandung di dalam peristiwa tersebut dapat memberikan sinyal bagi investor dalam mengambil suatu keputusan investasi. (Sari, Purnamawati, and Herawati 2017)Investor dalam membeli saham tidak terlepas dari kondisi pasar modal yang mencangkup berbagai informasi yang saling berhubungan dengan harga saham yang diperjualbelikan. Secara umum, informasi yang diperlukan investor dapat berasal dari kondisi internal ataupun eksternal perusahaan (emiten). Dalam pasar modal yang efisien, pasar akan bereaksi dengan cepat terhadap semua informasi yang relevan. Informasi yang terkandung dalam peristiwa tersebut dapat dilihat sebagai sinyal positif yang berkualitas baik (good news) maupun sinyal negatif yang berkualitas buruk (bad news). Reaksi pasar modal atas pengumuman tersebut dapat ditunjukkan dengan adanya perubahan pada harga saham dan volume pada perdagangan saham. (Sari, Purnamawati, and Herawati 2017).

Beberapa penelitian terdahulu yang menganalisis dampak peristiwa di pasar modal adalah penelitian yang dilakukan oleh $\mathrm{Ni}$ Putu Tila Permata Sari, Gusti Ayu Purnamawati, dan Nyoman Trisna Herawati (2017) dengan judul analisis komparatif saham LQ45 sebelum dan sesudah pilpres amerika serikat 2016. Penelitian tersebut menemukan bahwa tidak terdaat perbedaan rata-rata abnormal return yang signifikan sebelum maupun sesudah peristiwa pilpres Amerika Serikat 2016. (Sari, Purnamawati, and Herawati 2017). Penelitian serupa juga dilakukan oleh Kadek Ria Kusumayanti dan Anak Agung Gede Suarjaya dengan judul reaksi pasar modal indonesia terhadap pengumuman kemenangan donald trump 
dalam pilpres amerika serikat 2016, didalam penelitian tersebut mendapatan hasil bahwa terdapat abnormal return yang signifikan (Kusumayanti and Suarjaya 2018).

Namun berbagai penelitian peristiwa di pasar modal belum adanya yang meneliti terhadap reaksi pasar modal Indonesia terhadap keputusan pengumuman Indonesia sebagai negara maju, sehingga penelitian ini berusaha untuk membuktikan apakah harga saham-saham masih stabil, naik atau bahkan menurun, dan saham apa saja yang bereaksi di Bursa Efek Indonesia.

\section{KAJIAN LITERATUR}

\section{Signallling Theory}

Signalling theory adalah sebuah teori yang membahas tentang naik turunnya harga saham di pasar, sehingga dapat mempengaruhi keputusan investor (Fahmi ,2012:103). Menurut Suwardjono (2010:583), signaling theory berlandaskan pada teori akuntansi pragmatic yang berfokus pada pengaruh suatu informasi (Rahmawati 2014). Apapun informasi yang terjadi dari kondisi saham suatu perusahaan akan selalu memberikan pengaruh bagi keputusan investor sebagai pihak yang menangkap sinyal tersebut.informasi yang relevan, tepat, akurat, dan tepat waktu sebagai alat analisis untuk membantu investor dalam membuat keputusan investasi. Informasi yang telah dipublikasikan dalam bentuk pengumuman akan memberikan sinyal bagi investor dalam pengambilan keputusan saat berinvestasi (Sedana 2018).

Menurut Samsul (2006) banyak peristiwa yang dapat mempengaruhi harga saham di pasar modal begitu peristiwa itu terjadi atau peristiwa tersebut diumumkan. Peristiwa-peristiwa tersebut memiliki karakteristik yang berbeda. Peristiwa isidentiil yang tidak akan terjadi kembali setiap tahun tetapi dapat terjadi sewaktuwaktu atau kapan saja, seperti ledakan bom, kerusuhan massa dalam pergantian presiden, embargo ekonomi, memiliki efek secara langsung dan drastis pada harga saham di pasar modal. Peristiwa dapat memberikan dampak positif dan negatif terhadap penilaian para investor lokal dan calon investor, terutama bagi investor dan calon investor asing dikarenakan informasi yang terkandung dalam peristiwa tersebut dapat memberikan sinyal kepada investor dalam mengambil keputusan investasi, mengingat bahwa pasar modal Indonesia didominasi oleh pemodal asing, yang akan membuat para investor merasa aman untuk menginvestasikan dananya di pasar modal (Sedana 2018). Dalam mempelajari pengaruh suatu peristiwa terhadap bursa saham dapat menggunakan studi peristiwa (event study) (Sari, Purnamawati, and Herawati 2017).

\section{Pasar Modal}

Pasar modal adalah tempat untuk melakukan transaksi modal jangka panjang (Fabozi \& Modigliani, 2003:10), dimana permintaan diwakili oleh perusahaan yang menerbitkan surat berharga dan melakukan penawaran kepada investor. Namun, kata tempat di sini tidak mewakili lokasi seperti layaknya pasar konvensional. Karena transaksi tidak selalu dilakukan di tempattempat tertentu yang bersifat permanen. Bahkan, dengan adanya perkembangan ebusiness, transaksi di pasar modal juga dapat dilakukan di dunia maya melalui internet trading. Demikian pula yang dimaksud modal disini bukan dalam artian fisik uang tetapi uang yang sebagimana dinyatakan dalam bentuk sekuritas, yaitu saham dan obligasi serta turunannya (Widoatmodjo 2015). Menurut Kamus Besar Bahasa Indonesia (KBBI) pengertian pasar modal adalah seluruh aktivitas yang mempertemukan penawaran dan permintaan atau merupakan aktivitas yang memperjualbelikan surat-surat berharga (Nasarudin 2004). 
Menurut Tandelilin (2010), pasar modal efisien adalah pasar modal dimana harga semua sekuritas yang diperdagangkan telah mencerminkan informasi yang telah tersedia. Tujuan investor untuk menginvestasikan modalnya agar memperoleh keuntungan (return) yang maksimal dengan risiko tertentu. Dengan adanya pasar modal, investor dapat mendiversikasi investasi dengan membentuk portofolio seusai dengan keuntungan (return) yang telah diharapkan dan risiko tertentu dengan tingkat keuntungan yang maksimum atau tingkat keuntungan tertentu dengan risiko yang rendah (Jogiyanto 2017) (Verawaty, Noviardy, and Salindra 2018).

Dalam pasar modal terdapat pasar perdana dan sekunder. Pasar perdana (primary market) adalah pasar untuk penerbitan baru. Di pasar inilah dana dikumpulkan dengan melalui penjualan arus sekuritas baru dari para pembeli sekuritas tersebut (sektor simpanan) kepada para penerbit sekuritas (sektor investasi). Sedangkan pasar sekunder menurut Brealey, et al, (2008:160) adalah pasar tempat sekuritas yang telah diterbitkan sebelumnya diperdagangkan diantara investor. Dipasar sekunder (secondary market), semua sekuritas yang telah ada dibeli dan dijual. (Horne dan Machowicz, 2007:322) (Jusman 2019).

\section{Event Study}

Menurut Bowman (1983) dalam Hartono (2010), study peristiwa (event study) adalah study yang melibatkan analisis perilaku harga sekuritas sekitar waktu pada suatu peristiwa atau pengumuman informasi. Studi peristiwa adalah study yang mempelajari reaksi pasar terhadap suatu peristiwa yang informasinya diumumkan sebagai suatu pengumuman dan dapat digunakan untuk menguji kandungan informasi dari suatu pengumuman tersebut
(Dwianto and Yulita 2019). Sedangkan Jogiyanto (2003) menyatakan bahwa event study merupakan study yang mempelajari reaksi pasar terhadap suatu peristiwa (event) yang informasinya dipublikasikan sebagai suatu pengumuman (Fauzi and Ichsan 2018). Jogiyanto (2015:623) juga menyatakan bahwa event study adalah studi yang mempelajari reaksi pasar terhadap suatu peristiwa (event) yang informasinya dipublikasikan sebagai suatu pengumuman. Event study juga dapat digunakan untuk menguji efisiensi pasar bentuk setengah kuat. Secara lebih spesifik study peristiwa menyelidiki respon pasar terhadap kandungan informasi yang ada dari suatu pengumuman peristiwa tertentu (Kusumayanti and Suarjaya 2018).

Menurut Jogiyanto beberapa manfaat mengapa study peristiwa banyak digunakan, yaitu untuk menganalisis pengaruh dari suatu peristiwa terhadap nilai perusahaan, mengukur langsung pengaruh peristiwa tersebut terhadap harga saham perusahaan terhadap terjadinya peristiwa karena harga saham tersedia pada saat peristiwanya terjadi, dan kemudahan mendapatkan datanya (Jusman 2019). Event Study dapat digunakan untuk menguji kandungan informasi (information content) dari suatu pengumuman dan dapat juga digunakan untuk menguji efisiensi pasar dalam bentuk setengah kuat (Yusniar and Jikrillah 2018). Secara umum, informasi yang diperlukan oleh investor dapat berasal dari kondisi internal ataupun eksternal suatu perusahaan (emiten). Dalam pasar modal yang efisien, pasar akan merespon dengan cepat semua informasi yang relevan. Hal ini dapat ditunjukkan oleh perubahan harga saham yang melebihi kondisi normal, sehingga menimbulkan terjadinya abnormal return (Zaqi 2006). 


\section{Indeks Saham LQ45}

Indeks LQ-45 adalah salah satu indikator indeks pasar saham Indonesia, LQ 45 sendiri adalah indeks gabungan dari 45 emiten dengan likuditas tinggi, yang mana dalam pemilihan emiten agar termasuk dalam indeks LQ 45 dilakukan seleksi dengan beberapa kriteria pemilihan. Sejak diluncurkan pada bulan Februari 1997 ukuran utama likuiditas transaksi suatu emiten ditentukan dari nilai transaksi di pasar reguler. Sesuai dengan perkembangan pasar dan untuk lebih mempertajam kriteria likuiditas, maka sejak review bulan Januari 2005, jumlah hari perdagangan dan frekuensi transaksi dimasukkan sebagai ukuran likuiditas (Polakitan 2015).

Untuk menentukan saham-saham yang termasuk LQ 45, maka digunakan dua tahap seleksi. Tahap pertama, kriteria yang harus dipenuhi adalah : Saham tesebut berada di top 95 persen dari total rata-rata tahunan nilai transaksi saham di pasar reguler, berada di top 90 persen dari ratarata tahunan kapitalisasi pasar dan trcatat di BEI minimum 30 hari bursa. Jika lolos tahap pertama, maka dilanjutkan tahap berikutnya. Tahap kedua menyangkut kriteria sebagai berikut:merupakan urutan tertinggi yang mewakili sektornya dalam klasifikasi industri BEI, memiliki porsi yang sama dengan sektorsektor lain dan Merupakan urutan tertinggi berdasarkan frekuensi transaksi. Indeks LQ45 ini menggunakan metode ratarata tertimbang (weighted average) dengan rumus Paasche. Seperti yang digunakan pada IHSG BEl. Jadi jelas dari kriteria yang ditetapkan akan meloloskan sahamsaham yang mempunyai kapitalisasi pasar serta likuiditas tinggi (Polakitan 2015).

Bursa Efek Indonesia secara rutin memantau perkembangan kinerja emiten emiten yang masuk dalam penghitungan indeks LQ 45. Setiap tiga bulan sekali dilakukan evaluasi atas pergerakan urutan saham-saham tersebut. Penggantian saham akan dilakukan setiap enam bulan sekali, yaitu pada awal bulan Februari dan Agustus (Polakitan 2015).

\section{Abnormal Return}

Abnormal return adalah selisih antara tingkat keuntungan yang sebenarnya (actual return) dengan tingkat keuntungan yang diharapkan (expected return), sering disebut juga seabagai return tak normal yang dapat diartikan sebagai return yang diperoleh dari investasi dalam kondisi yang tak normal atau saat ada informasi maupun peristiwa baru yang terjadi sehingga mengubah nilai perusahaan dan memungkinkan investor bereaksi dalam bentuk kenaikan pada harga saham atau sebaliknya (Hartono, 2013:586). Abnormal return sering digunakan sebagai dasar untuk menguji efisiensi pasar, dan juga dapat digunakan untuk melakukan penilaian kinerja surat berharga (Zoraya et al. 2020). Menurut Jogiyanto (2015:205) actual return adalah return yang telah terjadi yang dapat dihitung berdasarkan data historis (Jogiyanto, 2015:648). Sedangkan return ekspektasi merupakan return yang diharapkan akan diperoleh oleh investor di masa mendatang. Hartono (2000) mengemukakan "beberapa pengukuran return realisasi yang banyak digunakan adalah return total (total returns), relatif return (return relative), kumulatif return (return cumulative) dan return disesuaikan (adjusted return)"(Susilawati 2009). Return realisasi dihitung berdasarkan data-data historis. Return historis berguna sebagai dasar untuk menentukan return ekspektasi dan risiko di masa yang akan datang (Jogiyanto, 2010:107) (Wijaya and Gunawan 2019).

Dapat disimpulkan bahwa abnormal return adalah selisih antara imbal hasil sesungguhnya yang telah terjadi dengan 
imbal hasil ekspektasi atau harapan. Jika suatu peristiwa tidak menyebabkan suatu abnormal return, berarti para investor tidak bereaksi atau pasar tidak bereaksi, karena reaksi dari para investor terhadap informasi yang baru ditunjukkan oleh abnormal return (Jogiyanto Hartono 2010). Begitu juga sebaliknya, jika abnormal return signifikan, maka para investor merespon kebijakan atau peristiwa tersebut ( $\mathrm{S}$, Yuniarta, and Sujana 2017).

Pengumuman Indonesia sebagai negara maju merupakan salah satu peristiwa dalam negeri yang mungkin dapat mempengaruhi aktivitas pasar modal. Hal ini dikarenakan informasi yang terkandung dalam peristiwa tersebut dapat dijadikan pertimbangan investor untuk pengambilan keputusan investasi. Seberapa besar kandungan yang ada pada informasi tersebut dapat terlihat dari bagaimana pasar bereaksi atas peristiwa tersebut. Reaksi pasar modal atas peristiwa tersebut ditandai dengan adanya perubahan pada harga saham. Dalam mengukur reaksi pasar tersebut menggunakan abnormal return (Sari, Purnamawati, and Herawati 2017).

Apapun informasi yang terjadi dari kondisi saham suatu perusahaan akan selalu memberikan efek bagi keputusan investor sebagai pihak yang menangkap sinyal tersebut. Informasi yang lengkap, relevan, akurat dan tepat waktu sangat diperlukan oleh investor di pasar modal sebagai alat untuk menganalisis pengambilan keputusan investasi. Informasi yang dipublikasikan sebagai suatu pengumuman dapat memberikan sinyal bagi para investor untuk membuat keputusan investasi (Sedana 2018).

\section{METODE PENELITIAN}

Pendekatan dalam penelitian ini menggunkan metode kuantitatif. Pendekatan penelitian kuantitatif dalam penelitian ini didukung dengan menggunakan pendekatan studi peristiwa (event study). Pendekatan ini akan digunakan untuk menganalisis reaksi pasar modal Indonesia terhadap peristiwa pengumuman Indonesia sebagai negara maju. Dalam penelitian ini studi peristiwa yang akan diuji kandungan informasinya adalah peristiwa pengumuman Indonesia sebagai negara maju pada tanggal 10 Februari 2020. Sumber data yang digunakan dalam penelitian ini yaitu dari sumber data sekunder.

Sampel menurut Sugiyono (2013), bagian dari jumlah dan karakteristik yang diperoleh oleh populasi tersebut. Sugiyono (2013) juga mengatakan bahwa apa yang dipelajari dari sampel akan dapat diberlakukan kepada seluruh populasi. Sampel yang digunakan dalam penelitian ini adalah saham yang termasuk anggota indeks LQ45. Populasi menurut Sugiyono (2013), adalah area generalisasi yang terdiri atas subjek atau objek yang memiliki kuantitas dan karakteristik tertentu yang telah ditetapkan oleh peneliti untuk dipahami dan kemudian ditarik kesimpulannya. Populasi dalam penelitian ini yaitu seluruh saham LQ45. Alasan menggunakan perusahaan LQ-45 dalam penelitian ini dikarenakan perusahaan LQ-45 merupakan 45 perusahaan denagn tingkat likuiditas yang tinggi sehingga reaksi pasar yang terjadi akibat peristiwa pengumuman Indonesia sebagai negara maju dapat terlihat dengan jelas dan akurat. Metode pengumpulan data yang akan digunakan dalam penelitian ini adalah dokumentasi. Pengumpulan data dilakukan dengan cara menelusuri data harga saham, jumlah saham yang diperdagangkan, jumlah saham yang beredar, dan nilai indeks. Penelitian ini dilakukan pada website resmi Bursa Efek Indonesia yaitu www.idx.co.id.

Variabel yang akan dianalisis dalam penelitian ini adalah abnormal return. Abnormal Return adalah selisih antara return 
sesungguhnya yang terjadi dengan return ekspektasi atau harapan.

\section{Teknik Analisis Data}

Penelitian ini merupakan event study menggunakan even windows 15 hari. Yaitu tujuh hari sebelum event day dan tujuh hari setelah event day, hal ini bertujuan dengan semakin tinggi pengamatan event day yang dilakukan diharapkan semakin efektif pula nilai statistik yang akan diperoleh.

Analisis dalam penelitian ini adalah sebagai berikut:

1. Menghitung abnormal return

Rumus Abnormal Return:

$\mathrm{RTN}_{\mathrm{it}}=\mathrm{R}_{\mathrm{it}}-\mathrm{E}\left(\mathrm{R}_{\mathrm{it}}\right)$

Keterangan:

RTN $_{\text {it }}$ = abnormal return saham i pada periode peristiwa $t$

$\mathrm{R}_{\mathrm{it}} \quad=$ return realisasi saham $\mathrm{i}$ pada periode peristiwa $t$

$E\left(R_{i t}\right) \quad=$ return ekspektasi saham $\mathrm{i}$ pada periode peristiwa $t$

2. Menghitung rata-rata abnormal return

$\overline{A R}$ sebelum $\quad=\frac{\sum_{t=-3}^{t=-1} A R \text { sebelum }}{t}$

$\overline{A R}$ sesudah $\quad=\frac{\sum_{t=+3}^{t=+1} A R \text { sebelum }}{t}$

Keterangan:

$\overline{A R}$ sebelum : rata-rata abnormal return sebelum peristiwa
AR sebelum : rata-rata abnormal return sebelum peristiwa

$\overline{A R}$ sesudah : rata-rata abnormal return sesudah peristiwa

AR sesudah : abnormal return sesudah peristiwa

3. Melakukan uji normalitas data pada variabel abnormal return untuk mengetahui apakah data berdistribusi normal atau tidak.

4. Melakukan uji beda pada variabel abnormal return untuk menguji ada atau tidaknya perbedaan rata-rata.

\section{HASIL DAN PEMBAHASAN}

Penelitian ini bertujuan untuk mengetahui reaksi pasar keuangan dalam hal ini yaitu pasar modal terhadap peristiwa pengumuman Indonesia sebagai negara maju pada tanggal 10 Februari 2020. Banyaknya informasi yang dipublikasikan di pasar modal yang mempengaruhi adanya abnormal return, di antaranya peristiwa pengumuman Indonesia sebagai negara maju terhadap abnormal return melalui event study.

Berikut adalah indeks harga saham pada saat sebelum dan sesudah peristiwa pengumuman Indonesia sebagai negara maju, yaitu data open dan close pada harga saham LQ45. Data harga saham tersebut diperoleh dari website resmi Bursa Efek Indonesia yaitu www.idx.co.id.

Tabel 1.1

Indeks Saham pada Peristiwa Pengumuman Indonesia Sebagai Negara Maju

\begin{tabular}{cccc}
\hline Tanggal & Kode Indeks & Open & Close \\
\hline $30 / 1 / 2020$ & LQ45 & 1000,32 & 987,202 \\
\hline $31 / 1 / 2020$ & LQ45 & 987,202 & 961,976 \\
\hline $3 / 2 / 2020$ & LQ45 & 961,976 & 953,263 \\
\hline $4 / 2 / 2020$ & LQ45 & 953,263 & 964,84 \\
\hline $5 / 2 / 2020$ & LQ45 & 964,84 & 976,559 \\
\hline $6 / 2 / 2020$ & LQ45 & 976,559 & 975,706 \\
\hline $7 / 2 / 2020$ & LQ45 & 975,706 & 977,001 \\
\hline $10 / 2 / 2020$ & LQ45 & 977,001 & 968,342
\end{tabular}




\begin{tabular}{cccc}
$11 / 2 / 2020$ & LQ45 & 968,342 & 967,381 \\
\hline $12 / 2 / 2020$ & LQ45 & 967,381 & 960,98 \\
\hline $13 / 02 / 2020$ & LQ45 & 960,98 & 954,206 \\
\hline $14 / 02 / 2020$ & LQ45 & 954,206 & 953,954 \\
\hline $17 / 02 / 2020$ & LQ45 & 953,954 & 954,172 \\
\hline $18 / 02 / 2020$ & LQ45 & 954,172 & 956,277 \\
\hline $19 / 02 / 2020$ & LQ45 & 956,277 & 964,393 \\
\hline
\end{tabular}

(Sumber: www.idx.co.id)

Awal dari pengujian ini yaitu dengan menghitung rata-rata abnormal return (AAR) untuk pada perusahaan LQ45, kemudian hasil AAR ini dipilah menjadi 2 kelompok, yaitu AAR sebelum peristiwa terjadi dan AAR setelah peristiwa terjadi. Data inilah yang kemudian diuji signifikansinya dengan program SPSS., maka diperoleh rata-rata (mean) dan standar deviasi. Statistik deskriptif dilakukan untuk memperoleh gambaran secara umum data yang telah diolah. Hasil pengujian statistik deskriptif dapat dilihat pada tabel 1.2 sebagai berikut.

Tabel 1.2

Descriptive Statistics

\begin{tabular}{|c|r|r|r|r|r|}
\hline & N & Minimum & Maximum & Mean & Std. Deviation \\
\hline AR Sebelum & 7 & -2.00 & 1.00 & -.2857 & 1.11270 \\
AR Sesudah & 7 & -1.00 & 1.00 & .0000 & .57735 \\
Valid N (listwise) & 7 & & & & \\
\hline
\end{tabular}

(Sumber : Hasil SPSS, data diolah 2020)

Tabel 1.2 menunjukkan bahwa ratarata abnormal return sebelum pengumuman Indonesia sebagai negara maju adalah -2,00 dengan standar deviasi 1,11270. Rata-rata abnormal return sesudah pengumuman Indonesia sebagai negara maju adalah $-1,00$ dengan standar deviasi 0,57735. Sebelum pengujian hipotesis dilakukan uji normalitas data menggunakan Shapiro-Wilk karena sampel data kurang dari 50 .
Selanjutnya melakukan pengujian normalitas data dengan menggunakan uji normalitas Shapiro Wilk, dikarenakan sampel kurang dari 50. Jika data memiliki nilai yang signifikansinya lebih besar dari 0,05 maka data tersebut berdistribusi normal dan sebaliknya, apabila data tersebut memiliki nilai yang signifikansinya lebih kecil dari 0,05 maka data tersebut tidak berdistribusi normal (Raharjo,

2016).

Tabel 1.3

Tests of Normality

\begin{tabular}{|l|r|r|r|}
\hline & \multicolumn{3}{|c|}{ Shapiro-Wilk } \\
\cline { 2 - 4 } & Statistic & Df & \multicolumn{1}{c|}{ Sig. } \\
\hline AR Sebelum & .941 & 7 & .649 \\
AR Sesudah & .916 & 7 & .440 \\
\hline
\end{tabular}

(Sumber : Hasil SPSS, data diolah 2020

*. This is a lower bound of the true significance. 
a. Lilliefors Significance Correction

Berdasarkan tabel 1.3 nilai signifikan abnormal return sebelum pengumuman Indonesia sebagai negara maju adalah 0,649 > 0,05 sehingga data berdistribusi normal. Sedangkan data signifikan abnormal return sesudah pengumuman Indonesia sebagai negara maju adalah $0,440>0,05$ sehingga data berdistribusi normal. Jadi dapat disimpulkan bahwa kedua variable berdistribusi normal.

Pengujian hipotesis yang digunakan adalah uji paired sampel $t$ test karena data berdistrubusi normal. Dasar pengambilan dalam keputusan jika nilai signifikansinya < 0,05 maka hipotesis 1 diterima. Sedangkan jika nilai signifikansinya $>0,05$ maka hipotesis 1 ditolak.

Tabel 1.4

Paired Samples Test

\begin{tabular}{|c|c|c|c|c|c|c|c|c|c|}
\hline & \multicolumn{5}{|c|}{ Paired Differences } & \multirow[b]{3}{*}{$\mathrm{t}$} & \multirow[b]{3}{*}{$d f$} & \multirow{3}{*}{$\begin{array}{l}\text { Sig. } \\
(2- \\
\text { tailed })\end{array}$} \\
\hline & & \multirow[b]{2}{*}{ Mean } & \multirow{2}{*}{$\begin{array}{c}\text { Std. } \\
\text { Deviation }\end{array}$} & \multirow{2}{*}{$\begin{array}{l}\text { Std. Error } \\
\text { Mean }\end{array}$} & \multicolumn{2}{|c|}{$\begin{array}{l}\text { 95\% Confidence } \\
\text { Interval of the } \\
\text { Difference }\end{array}$} & & & \\
\hline & & & & & Lower & Upper & & & \\
\hline Pair 1 & $\begin{array}{l}\text { AR } \\
\text { Sebelum } \\
\text { AR } \\
\text { Sesudah }\end{array}$ & -2.57143 & 11.78781 & 4.45537 & -13.47333 & 8.33047 & -.577 & 6 & .585 \\
\hline
\end{tabular}

(Sumber : Hasil SPSS data diolah 2020)

Berdasarkan hasil perhitungan pada uji statistik analisis paired-sampel $t$ test dengan bantuan program Statistical Package for Social Science (SPSS) tabel 1.4 diperoleh hasil sig. (2-tailed) sebesar 0,585. Karena nilai sigfinikansinya 0,585 >0,05 maka hipotesis 1 ditolak, artinya tidak terdapat perbedaan pada rata-rata abnormal return yang signifikan sebelum dan sesudah pengumuman Indonesia sebagai negara maju. Tidak terjadinya reaksi yang signifikan menandakan bahwa pelaku pasar masih bersikap waspada dan memperhitungkan jangka panjang sehingga tidak terburu-buru dalam melakukan aktivitas di pasar modal. Hasil penelitian ini sejalan dengan hasil penelitian Ni Putu Tila Permata Sari, Gusti Ayu Purnamawati, dan Nyoman Trisna Herawati (2017) tentang analisis komparatif saham LQ45 sebelum dan sesudah pilpres Amerika Serikat 2016 menunjukkan bahwa tidak terdapat rata-rata abnormal return sebelum dan sesudah peristiwa pilpres Amerika Serikat 2016. Akan tetapi, penelitian ini tidak sejalan dengan hasil penelitian dari Kadek Ria Kusumayanti dan Anak Agung Gede Suarjaya (2018) dengan judul reaksi pasar modal Indonesia terhadap pengumuman kemenangan Donalnd Trump dalam pilpres Amerika Serikat 2016 menunjukkan bahwa adanya abnormal return yang signifikan.

Reaksi pasar modal yang dilihat dari abnormal return yang diterima oleh investor disekitar hari-hari peristiwa tersebut terjadi, menunjukkan kecepatan pasar dalam menyerap kandungan informasi yang diterima. Kecepatan reaksi pasar modal terhadap peristiwa tersebut bereaksi cepat karena terdapat abnormal return yang signifikan pada satu hari $(\mathrm{H}+1)$ setelah 
peristiwa. Namun abnormal return muncul kembali pada $\mathrm{H}+3, \mathrm{H}+4$ dan $\mathrm{H}+5$ menunjukkan bahwa pasar tidak efisien, karena reaksi terjadi berkepanjangan, seperti yang dinyatakan oleh Tandelilin (2010:223) bahwa pasar yang efisien bentuk setengah kuat, abnormal return hanya terjadi di seputar pengumuman (publikasi) pada suatu peristiwa sebagai representasi dari respon pasar terhadap pengumuman tersebut.

Namun, dari hasil penelitian ini menemukan bahwa pengumuman Indonesia sebagai negara maju tidak terjadi reaksi signifikan yang menandakan bahwa pelaku pasar masih bersikap waspada dan memperhitungkan kemungkinan jangka panjang sehingga tidak terburu-buru dalam melakukan aktivitas di pasar modal. Hal ini tercermin dari tidak adanya rata-rata abnormal return yang signifikan.

\section{IMPLIKASI PENELITIAN}

Bagi teoritis hasil penelitian ini memberikan informasi bahwa pengumuman Indonesia sebagai negara maju tidak menyebabkan perbedaan rata-rata abnormal return yang signifikan sebelum dan sesudah adanya peristiwa. Hal ini ditunjukkan nilai signifikansi 0,799 $>0,05$. Artinya reaksi pasar yang sebagian besar tidak signifikan ini mengakibatkan secara statistik tidak adanya perbedaan rata-rata abnormal return yang signifikan pada pengumuman Indonesia sebagai negara maju.

Bagi praktisi hasil penelitian ini digunakan sebagai informasi kepada investor sebagai bahan pertimbangan dalam membuat keputusan yang tepat. Dengan adanya penelitian ini tentunya diharapkan agar investor dapat jeli dan teliti dalam melihat informasi atau signaling untuk digunakan sebagai pertimbangan keputusan yang tepat di masa mendatang sehingga diharapkan pemegang saham dapat memperoleh abnormal return positif atas suatu peristiwa.

\section{SIMPULAN DAN SARAN}

Simpulan yang dapat diambil berdasarkan uji beda menggunakan paired sample $t$ test selama periode penelitian menunjukkan nahwa tidak terdapat perbedaan rata-rata abnormal return yang signifikan terhadap peristiwa tersebut. Berarti pasar tidak bereaksi atas peristiwa tersebut yang ditunjukkan dengan tidak adanya perubahan harga saham yang menyebabkan terjadinya abnormal return positif dari kondisi sebelum dan setelah event. Hal ini terjadi karena media telambat memberikan infomasi sehingga para investor tidak mengetahui informasi pada saat peristiwa pengumuman Indonesia sebagai negara maju berlangsung. Akibatnya para investor tidak dapat melakukan apa-apa dalam rangka merespon pengumuman tersebut.

Bagi peneliti selanjutnya disarankan untuk lebih menambah periode pengamatan. Selain itu agar menambah jumlah sampel penelitian yang tidak hanya terbatas pada perusahaan LQ45 dan menambah variabel dikarenakan dalam penelitian ini hanya menggunakan satu variabel saja. Dengan menambah varibael diharapkan untuk memperbanyak ilmu pengetahuan.

\section{DAFTAR PUSTAKA}

Benyamin, Maria Y., and Yustinus Andri. 2020 "Salah Kaprah! Ini Fakta-Fakta Soal Indonesia Dikeluarkan Dari List Negara Berkembang AS." https://m.bisnis.com/ekonomibisnis/read/20200226/12/1205740/salahkaprah-ini-fakta-fakta-soal-indonesiadikeluarkan-dari-;ist-negara-berkembang-as(March 14, 2020).

Dwianto, Nicholas Arditya, and Ima Kristina Yulita. 2019. "REAKSI PASAR MODAL INDONESIA TERHADAP PELUNCURAN RUDAL KOREA UTARA." Journal Of Research in Business and Economics 02(01): 22-40.

Fahmi, Irham. 2012. Manajemen Investasi Teori Dan Soal Jawab. Jakarta: Salemba Empat Foster. 
Fauzi, Muhammad Agus, and Nur Ichsan. 2018. "REAKSI PASAR MODAL SYARIAH TERHADAP AKSI BELA ISLAM 212 DI JAKARTA." Jurnal Ilmu Sosial-Humaniora 3: $65-82$.

Hartono, J. 2013. Teori Portofolio Dan Analisis Investasi. Yogyakarta: BPFE.

Hartono, Jogiyanto. 2010. Metodologi Penelitian Bisnis. Yogyakarta: BPFE.

Jogiyanto. 2010. Menguji Reaksi Pasar Modal Akibat Suatu Peristiwa. Yogyakarta: BPFE.

Jogiyanto, H.M. 2017. Teori Portofolio Dan Analisis Investasi. Yogyakarta: BPFE.

Jusman, Jumriaty. 2019. “ANALISIS REAKSI PASAR MODAL INDONESIA TERHADAP PERISTIWA PELEDAKAN BOM BUNUH DIRI DI SURABAYA (Studi Kasus Pada Perusahaan LQ 45 Yang Terdaftar Di Bursa Efek Indonesia) Jumriaty." Jurnal Ilmiah Ekonomi Bisnis: 200-209.

Kusumayanti, Kadek, and Anak Suarjaya. 2018. "REAKSI PASAR MODAL INDONESIA TERHADAP PENGUMUMAN KEMENANGAN DONALD TRUMP DALAM PILPRES AMERIKA SERIKAT 2016 Fakultas Ekonomi Dan Bisnis Universitas Udayana, Bali-Indonesia Email : Riakusuma95@gmail.Com ABSTRAK Pasar Modal Sebagai Salah Satu Instrumen Eko." E-Jurnal Manajemen Unud 7(4): 1713-41.

Movanita, Ambaranie Nadia Kemala. 2019. "Per Mei 2019, Investor Pasar Modal Indonesia Mencapai 1,9 Juta." https://money.kompas.com/read/2019/06/26/ 141032126/per-mei-2019-investor-pasarmodal-indonesia-mencapai-19-juta (March 14, 2020).

Mukaromah, Vina Fadhrotul. 2020. "Indonesia Dicoret AS Dari Daftar Negara Berkembang, Apa Plus Minusnya? Artikel Ini Telah Tayang Di Kompas.Com Dengan Judul 'Indonesia Dicoret AS Dari Daftar Negara Berkembang, Apa Plus Minusnya?", Kompas.com.

Nasarudin, Irsan. 2004. Aspek Hukum Pasar Modal Di Indonesia. Jakarta: Kencana.

Polakitan, Cendi D. 2015. "Analisis Komparasi Risiko Saham LQ 45 Dan Non LQ 45 Pada Beberapa Sub Sektor Perusahaan Yang Terdaftar Di Bursa Efek Indonesia (BEI)." Jurnal Riset Bisnis dan Manajemen 3(1): 6172.

Rahmawati, Intan Ayu. 2014. “ANALISIS
PERBEDAAN ABNORMAL RETURN SAHAM SEBELUM DAN SESUDAH PUTUSAN SIDANG SENGKETA PEMILU PRESIDEN 2014 ( Studi Kasus Saham Di Bursa Efek Indonesia )." Jurnal Akuntansi Aktual 3: 1-10.

S, Citra Heveanty Utami, Gede Adi Yuniarta, and Edy Sujana. 2017. "REAKSI INVESTOR DALAM PASAR MODAL TERHADAP PERISTIWA PADA NILAI TUKAR RUPIAH ( Event Study Pada Peristiwa Menguatnya Kurs Dolar AS Terhadap Nilai Tukar Rupiah Tanggal 26 Agustus 2015 ).” Jurnal S1 Akuntansi 07(1): 1-10.

Sari, Ni Putu Tila Permata, Guati Ayu Purnamawati, and Nyoman Trisna Herawati. 2017. "Analisis Komparatif Saham LQ45 Sebelum Dan Sesudah Pilpres Amerika Serikat 2016." E-journal S1 Ak Universitas Pendidikan Ganesha 7(1): 1-10.

Sedana, I B Panji. 2018. "REAKSI PASAR MODAL INDONESIA TERHADAP KEMENANGAN DONALD TRUMP PADA PILPRES 2016 DI AMERIKA SERIKAT." Jurnal Buletin Studi Ekonomi 23(1): 92-107.

Susilawati, R. Anastasia Endang. 2009. "REAKSI PASAR MODAL TERHADAP PENGUMUMAN." Jurnal Ekonomi Modernisasi 5: 57-69.

Tari, Dwi Nicken. 2019. "5 Tahun Jokowi-JK, Pasar Saham Kian Semarak." https://market.bisnis.com/read/20191015/7/1 159215/5-tahun-jokowi-jk-pasar-sahamkiansemarak.

Verawaty, Andrian Noviardy, and Muhammad Salindra. 2018. "PENGARUH AKSI DAMAI 212 TERHADAP ABNORMAL RETURN SAHAM PADA KELOMPOK INDEKS SAHAM LQ-45." Jurnal Ilmiah MBiA 17(3): 13-24.

Wareza, Monica. 2020. "Ini 4 Jurus OJK Kembangkan Pasar Modal Pada 2020." https://www.cnbcindonesia.com/market/2020 010212215-17-127084/ini-jurus-ojkkembangkan-pasar-modal-pada-2020 (March 14, 2020).

Widoatmodjo, Sawidji. 2015. Pengetahuan Pasar Modal Untuk Konteks Indonesia. Jakarta: PT Elex Media Komputindo.

Wijaya, Kartika, and Hendra Gunawan. 2019. "REAKSI PASAR MODAL INDONESIA TERHADAP KESEPAKATAN INVESTASI ANTARA PEMERINTAH." Journal of Business Administration 3(2): 306-16. 
Yusniar, Meina, and Sulfi Jikrillah. 2018. "Reaksi

Pasar Modal Dan Pasar Uang Dunia

Terhadap Pemilihan Presiden Amerika

Serikat 2016." Jurnal Inovasi Bisnis dan

Manajemen Indonesia 1(September): 51021.

Zaqi, M. 2006. Reaksi Pasar Modal Indonesia Terhadap Peristiwa-Peristiwa Ekonomi Dan Peristiwa-Peristiwa Sosial-Politik Dalam Negeri (Studi Kasus Saham LQ-45 Di Bursa Efek Jakarta Periode 19992003). Semarang: Universitas Diponegoro.

Zoraya, Intan et al. 2020. "DAMPAK PILKADA SERENTAK 27 JUNI 2018 TERHADAP ABNORMAL RETURN DAN AKTIVITAS VOLUME PERDAGANGAN SAHAM DI BEI." Jurnal Riset Manajemen dan Bisnis 5(1): 13-28. 